\title{
Erratum to: Spending more time with the customer: service providers' behavioral discretion and call-center operations
}

\author{
Gil Luria $^{1} \cdot$ Iddo Gal $^{1} \cdot$ Dana Yagil $^{1}$
}

Published online: 16 September 2015

(C) Springer-Verlag Berlin Heidelberg 2015

\section{Erratum to: Serv Bus (2015) 9:427-443 \\ DOI 10.1007/s11628-014-0232-3}

The names of all three authors were erroneously written in reversed order (family names erroneously replaced first names). The correct citation should be:

Luria, G., Gal, I., \& Yagil, D. (2015). Spending more time with the customer: service providers' behavioral discretion and call-center operations. Service Business, 9(3), 427-443.

The online version of the original article can be found under doi:10.1007/s11628-014-0232-3.

Gil Luria

gluria@univ.haifa.ac.il

Iddo Gal

iddo@research.haifa.ac.il

Dana Yagil

dyagil@research.haifa.ac.il

1 Department of Human Services, Faculty of Social Welfare and Health Sciences, University of Haifa, Mount Carmel, 31905 Haifa, Israel 